\title{
The Practicing and Attitude of Some Medical Students at Al-Nahrain College of Medicine Towards Cosmetic Rhinoplasty
}

\author{
Nibras Alaa Hussain ${ }^{1}$ Qais Ismaeel Kadhem ${ }^{2}$, Ashraf MA Hussain ${ }^{3}$ \\ ${ }^{\text {I} F I B M S, ~ M B C h B ; ~ A l-N a h r a i n ~ U n i v e r s i t y / C o l l e g e ~ o f ~ M e d i c i n e / ~ F a m i l y ~ \& ~ C o m m u n i t y ~ M e d i c i n e ~ D e p a r t m e n t / I r a q, ~}$ \\ ${ }^{2}$ Family and Community Department, College of Medicine, University of Babylon/Iraq, ${ }^{3}$ PhD Community, Family \\ and Community Department, College of Medicine, University of Babylon/Iraq
}

\begin{abstract}
Background: Rhinoplasty in universal is connected with cosmetic surgery carried out to produce alterations in the interior and exterior components on the nose for merely cosmetics good reasons to get better look. It was common cosmetic procedures around the world because the nasal deformities effect on the psychology of the person as a negative impact on their self-confidence and social interaction with others.
\end{abstract}

Objectives: The study is an attempt to display the practicing and attitude of some medical students towards cosmetic rhinoplasty and its relation to some studied variables.

Methods: A cross-sectional study was conducted at Al-Nahrain medical college, during March 2016. A total of 200 undergraduate students were given a semi constructed questionnaire .The sample selected randomly by systematic random sampling.

Results: The practicing of rhinoplasty among this sample was $10.5 \%$. Most of them happy with their nose appearance. $56.5 \%$ of the sample see this surgery socially accepted in Iraq. There was significant relation between person undergoing rhinoplasty and presence of family history of it.

Conclusion: More than half of the medical student found cosmetic rhinoplasty is socially accepted in Iraq. Despite the majority of them had no family history of undergoing rhinoplasty but there was significant difference between doing such surgery and the presence of family history. More than two third of the students included in this study like more awareness program on cosmetic surgery.

Recommendation: Encouragement for more studies to be done for this subject, and developing an educational program to increase awareness about rhinoplasty.

Keywords: rhinoplasty, attitude, cosmetic.

\section{Introduction}

Among males and females the nose aesthetic is become occupied, the nose due to it's central prominent part of the face, so when the nose is taller than other facial part of face or not complement the face, it can affect self-perception and confidence. ${ }^{(1)}$

Rhinoplasty in universal is connected with cosmetic surgery carried out to produce alterations in the interior and exterior components on the nose for merely cosmetics good reasons to get better look. ${ }^{(2)}$
Currently there is always a developed picture attention among a variety of racial and ethnic communities around the world. Possibly because individuals living longer, a larger feeling of self-stem driven by way a person's looks are suffering from, (3) and the nasal deformities effect on the psychology of the person as a bad effect on their self-confidence and public communication with others (4). Rhinoplasty presently increasing everywhere in the world, particularly in the Gulf countries, according to the statistics done worldwide; it is become the fifth most usually done plastic technique international. ${ }^{(5)}$ While 
in Saudi Arabia it is the second most common plastic surgery. ${ }^{(6)}$

Plastic rhinoplasty customized to repair, reconstruct or replace any physical defect due to: ( Birth disorders, Trauma, Burns, Developmental abnormalities, Infections, Tumors, Preference and self-choice). ${ }^{(7)}$

\section{Complications of Rhinoplasty include:} (Complications of anesthesia. Epistaxis, Septal perforation and hematoma, Unsatisfactory appearance and deformity, Infection, Worsening rather than improvement in shape or in the nasal functions). ${ }^{(8)}$

In Iraq despite their lifestyle was largely dedicated by costumes, traditions and some religious interpretation, there has been growing interest in the past few years in cosmetics procedures, especially in rhinoplasty. And their plastic surgeons have gained huge experiences and skills in reconstructive and cosmetic surgery to help rehabilitate many thousands of people wounded by bombs or bullets. ${ }^{(9)}$

\section{Subjects and Method}

A cross-sectional study was adopted at Al-Nahrain College of medicine. The sample selected randomly by systematic random sampling and choose 200 students, during March and April 2016, were given a semi constructed questionnaire especially prepared for this study and collected by the fourth year students, which include Demographic information e.g. age in years, gender, stage order, father and mother education in years and attitude questions like:

(How do you feel about your nose?, In the past, Have you had cosmetic Rhinoplasty ?, Do you think cosmetic Rhinoplasty are necessary ?, Family history of having cosmetic procedures?....)

Data was translated into a computerized data base structure .Statistical analysis was done by using SPSS Version (20) computer software and Microsoft Excel 2010 used to draw figures present in this study .
Verbal consent was taken from all participants before they answered the questionnaire.

\section{Result}

Among 200 students there were 86 (43\%) males and $114(57 \%)$ females. The percent of students whom practicing rhinoplasty among this sample was $10.5 \%$. See figure 1

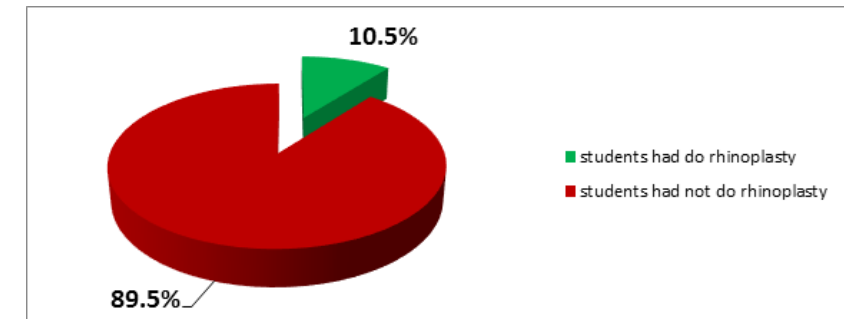

Figure-1- The percent of students whom practicing rhinoplasty among the sample from Al-Nahrain medical students,2016.

-All college stages were included in this study according to their total numbers, first stage $=33(16.5 \%)$, second stage 37(18.5\%), third stage 39(19.5\%), fourth stage $34(17 \%)$, fifth stage $30(15 \%)$ and sixth stage $27(13.5 \%)$. See figure -2-

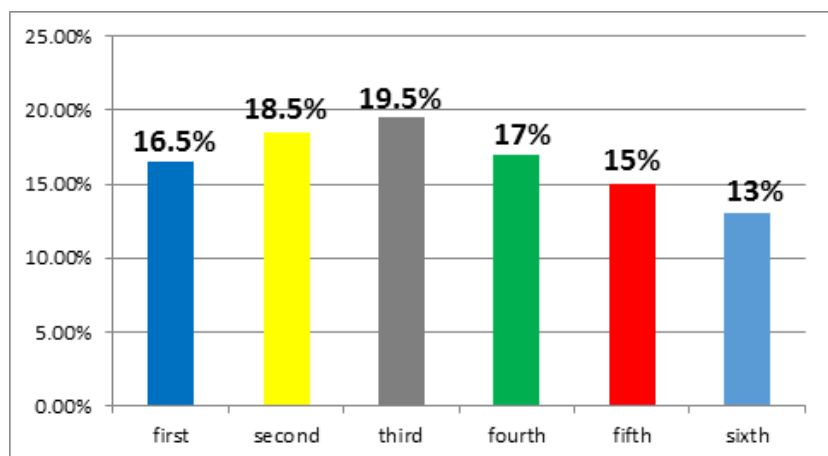

Figure-2- Distribution of the sample according to the student's stages in Al-Nahrain medical college, 2016.

-The age of the study group ranged $(17-25)$ years with mean $\pm \mathrm{SD}(21.2 \pm 1.76)$ years.

-Concerning the questions about the attitudes of ALNahrain Medical Students towards cosmetic rhinoplasty. See table1

Table(1):- Attitudes of the sample of Al-Nahrain medical students towards cosmetic rhinoplasty .

\begin{tabular}{|l|l|l|}
\hline Questions & Attitude & Numbers (\%) \\
\hline & Happy & $96(48 \%)$ \\
1 - feeling about Your nose & Not happy & $37(18.5 \%)$ \\
& Don't care & $67(33.5 \%)$ \\
\hline
\end{tabular}


Cont... Table(1):- Attitudes of the sample of Al-Nahrain medical students towards cosmetic rhinoplasty .

\begin{tabular}{|c|c|c|}
\hline 2- any previous cosmetic Rhinoplasty? & $\begin{array}{l}\text { Yes } \\
\text { No }\end{array}$ & $\begin{array}{l}21(10.5 \%) \\
179(89.5 \%)\end{array}$ \\
\hline 3 -are rhinoplasty necessary? & $\begin{array}{l}\text { Yes } \\
\text { No } \\
\text { Not sure }\end{array}$ & $\begin{array}{l}57(28.5 \%) \\
76(38 \%) \\
67(33.5)\end{array}$ \\
\hline 4-any family history of cosmetic intervention? & $\begin{array}{l}\text { Yes } \\
\text { No }\end{array}$ & $\begin{array}{l}30(15 \%) \\
170(85 \%)\end{array}$ \\
\hline 5 -your friend has previous cosmetic surgery? & $\begin{array}{l}\text { Yes } \\
\text { No }\end{array}$ & $\begin{array}{l}102(51 \%) \\
98(49 \%)\end{array}$ \\
\hline 6- you embarrassed from cosmetic procedures if anybody identified about it? & $\begin{array}{l}\text { Yes } \\
\text { No }\end{array}$ & $\begin{array}{l}59(29.5 \%) \\
141(70.5 \%)\end{array}$ \\
\hline 7- You support your friends experiencing cosmetic procedures if they told you? & $\begin{array}{l}\text { Yes } \\
\text { No } \\
\text { Uncertain }\end{array}$ & $\begin{array}{l}96(48 \%) \\
51(25.5 \%) \\
53(26.5 \%)\end{array}$ \\
\hline $\begin{array}{l}\text { 8-If cosmetic surgeries were done free, would you go for any cosmetic } \\
\text { operation? }\end{array}$ & $\begin{array}{l}\text { Yes } \\
\text { No } \\
\text { Not sure }\end{array}$ & $\begin{array}{l}55(27.5 \%) \\
94(47 \%) \\
51(25.5 \%)\end{array}$ \\
\hline $\begin{array}{l}\text { 9-If you were cognizant that somebody did cosmetic surgery, this effect on } \\
\text { relationship with him? }\end{array}$ & $\begin{array}{l}\text { Yes } \\
\text { No } \\
\text { Not sure }\end{array}$ & $\begin{array}{l}16(8 \%) \\
141(70.5 \%) \\
43(21.5 \%)\end{array}$ \\
\hline 10 -it is socially accepted in Iraq? & $\begin{array}{l}\text { Yes } \\
\text { No } \\
\text { Not sure }\end{array}$ & $\begin{array}{l}113(56.5 \%) \\
29(14.5 \%) \\
58(29 \%)\end{array}$ \\
\hline 11-If (10) yes, to how much it is acceptable? & $\begin{array}{l}\text { Widely } \\
\text { Averagely } \\
\text { Not acceptable }\end{array}$ & $\begin{array}{l}29(14.5 \%) \\
135(67.5 \%) \\
36(18 \%)\end{array}$ \\
\hline 12-any awareness program on cosmetic operation? & $\begin{array}{l}\text { Yes } \\
\text { No } \\
\text { Not sure }\end{array}$ & $\begin{array}{l}142(71 \%) \\
32(16 \%) \\
26(13 \%)\end{array}$ \\
\hline
\end{tabular}

\section{Comparing students, who had rhinoplasty and those had not:-}

There was no significant association regarding the gender of the students and the history of doing rhinoplasty $(\mathrm{P}=0.36)$. See table (2).

-Table (2) Rhinoplasty according to the gender of Al-Nahrain medical students.

\begin{tabular}{|l|l|l|l|l|}
\hline Gender & Do rhinoplasty & Don't do rhinolasty & Total & Significance \\
\hline Male & $11(12.8 \%)$ & $75(87.2 \%)$ & $86(100 \%)$ & \multirow{2}{*}{$\begin{array}{l}\mathbf{X}^{2}=0.842 \\
\mathrm{P}=0.36\end{array}$} \\
\cline { 1 - 4 } & $10(8.8 \%)$ & $104(91.2 \%)$ & $114(100 \%)$ & \\
\hline
\end{tabular}

-While there was significant difference between gender of students and the attitude of their relation with a person who undergo rhinoplasty ( $\mathrm{P}=0.002)$. See table (3). 
Table (3) Negatively effect of operation on the student relation according the gender.

\begin{tabular}{|l|l|l|l|l|l|}
\hline Gender & Yes & No & Not sure & Total & Significance \\
\cline { 1 - 5 } Male & $13(15.1 \%)$ & $60(69.8 \%)$ & $13(15.1 \%)$ & $86(100 \%)$ & $\begin{array}{l}\mathrm{X}^{2}=12.422 \\
\mathrm{P}=0.0022\end{array}$ \\
\cline { 1 - 5 } Female & $3(3.6 \%)$ & $81(71.1 \%)$ & $30(26.3 \%)$ & $114(100 \%)$ & \\
\hline
\end{tabular}

-Finally there was significant relation between undergoing rhinoplasty and the presence of family history of doing such surgery at $(\mathrm{P}=0.002)$. See table (4).

Table (4) Family history association of undergoing rhinoplasty and doing such surgery.

\begin{tabular}{|l|l|l|l|l|}
\hline & Family history & No family history & Total & Significance \\
\hline Had rhinoplasty & $8(38.1 \%)$ & $13(61.9 \%)$ & $21(100 \%)$ & $\begin{array}{l}\mathrm{X} 2=9.816 \\
\mathrm{P}=0.002 \\
\mathrm{Df}=1\end{array}$ \\
\hline Had not rhinoplasty & $22(12.3 \%)$ & $157(87.7 \%)$ & $179(100 \%)$ & \\
\hline
\end{tabular}

\section{Discussion}

The concerning about the appearance is progressively increase both in the developed and the developing countries, so this lead to increase in cosmetic surgeries done yearly ${ }^{(10)}$. The mean age of student involved in our study was similar to study done by Ahmed M.... et al in Pakistan ${ }^{(11)}$ and by Tanthry D...et al in India ${ }^{(12)}$, this is due to the sample take in our study and samples of them is taken from the college whom their age closely in the same variety.

The prevalence of rhinoplasty was $10.5 \%$ in this study and this more than the global percentage $8.2 \%$ , ${ }^{(5)}$ and this may be due to selection of the sample from medical students whom more aware about this surgery, also the age of them which had tendency to do such procedure.

Regarding their satisfaction about their nose appearance, it was found that less than half of the sample were happy about their nose appearance like what was found in Iran Aliasghar M....et al. ${ }^{(8)}$

Most of the students included in this study see rhinoplasty surgery as not necessary like what Rozin.... et al found, as they preferred the natural things over unnatural things. ${ }^{(13)}$

The majority of this sample $70.5 \%$ were not embarrassed about undergoing cosmetic procedures and this like what was found in London by Swami V ...et al. ${ }^{(14)}$.
Regarding socially acceptance of rhinoplasty more than half found it socially accepted in Iraq and this like what found by Swami V. ....et al. ${ }^{(14)}$ This may represent the opinion of medical students and not all Iraqi's people. Concerning the students relationship with a person undergoing rhinoplasty, about two third of them their relation were not affected negatively, and this like what found by Swami V....et al in London, (14) while Delinsky in United States found there was a negatively affect on relationship with such person. ${ }^{(15)}$

Less than third of the included students in this study like to do cosmetic surgery if it was done free in Iraq, and this nearly like what found by AL Mohanna Sh.... et al in Saudia Arabia. ${ }^{(16)}$

$2 / 3$ of the defendants suggested the need for more consciousness of beautifying operation in the culture like what was originate in Nigeria by Opeyemi A.... et al in 2014. ${ }^{(17)}$

Regarding the gender there was no significant difference in doing rhinoplasty and this like what found in Nigeria, ${ }^{(17)}$ while in other study done in Saudia found significant relation between both gender ${ }^{(16)}$ and this may be due to take the sample whom had nearly same sociodemographic and educational levels.

Also there was significant relation between male and female according to their relationship with a person who undergo rhinoplasty, this like what Swami V. ... et al. ${ }^{(14)}$ 
Finally this study found a significant relation between doing rhinoplasty and the presence of the family history of rhinoplasty and this like what was found in Iran ${ }^{(8)}$ and in Saudia. ${ }^{(16)}$ And this means friends and relatives influence a major motive for undergoing cosmetic rhinoplasty.

\section{Conclusion}

As the number of rhinoplasty operations are increase, so further research concerning the reason of this increase. It also recommend doing more movements to increase consciousness toward rhinoplasty problems.

Ethical Clearance: The Research Ethical Committee at scientific research by ethical approval of both environmental and health and higher education and scientific research ministries in Iraq

Conflict of Interest: The authors declare that they have no conflict of interest.

Funding: Self-funding

\section{References}

1. Piromchai P, Suetrong S and Arunopongpaisal S. Psychological status in patients seeking Rhiniplasty. Clinical medicine insights: Ear, Nose and Throat 2011: 431-35.

2. Understanding the difference between "cosmetic" and "plastic" surgery. The American Board of Cosmetic Surgery. Available: (http://www. americanboardcosmeticsurgery.org/How-WeHelp/cosmeticsurgery-vs-plastic-surgery.html.

3. Panse N, Panse S, Kulkarni P....et al. Awareness and perception of plastic surgery among health care professionals in Pune; India, Do they really know what we do?. Plastic Surgery International 2012; 10 ; 1155-64.

4. Castle DJ, Honigman RJ, Philips KA. Does cosmetic surgery improve psychosocial wellbeing? Med J Aust 2002; 176:601-4[PubMed]

5. International Society of Aesthetic Plastic Surgery. ISAPS International survey on Aesthetic/Cosmetic; 2013. Retrieved from (http://www.isaps.org/news/ isaps-global-statistics).

6. International Society of Aesthetic Plastic Surgery. ISAPS International survey on Aesthetic/Cosmetic; 2010. Retrieved from (http://www.isaps.org/news/ isaps-global-statistics).
7. Reid AJ and Malone Ps. "Plastic surgery in the press". Journal of plastic ,Reconstructive and Aesthetic surgery;2008; 61(8): 866-869.

8. Miamroodi AA, Eslami M, Khanjani N. Interest in Rhinoplasty and Awareness about its postoperative complications among female high school students. Iranian Journal of Otorhinolaryngology; April 2012; 24(68):135-43.

9. More cosmetic surgery in Iraq after drop in violence. 2010. Available at (http://www.bbc.com/ news/world/middle east).

10. American Society for Aesthetic Plastic Surgery. Quick facts:Highlights of the ASAPS 2007 statistics on cosmetic surgery.2008. Online publication at (http://www.surgery.org).

11. Ahmed M, Mohammed H, Ahmed N . View of college students on plastic surgery. World J plast surgery $2013 ; 2(2) ; 104-110$.

12. Tanthry D, Tanthry G, Devan PP....et al. Awareness about rhinoplasty among health care professionals in a tertiary referral center across -sectional study . Int J Biol Med Res. 2012; 3(4): 2471_2474.

13. Rozin P. (2006). Naturalness judgments by lay Americans: Process dominates content in judgments of food or water acceptability and naturalness. Judgment and Decision Making; 1; 91-97.

14. Swami V, Chamorro-Premuzic T, Bridges S, \& Furnham A. Acceptance of cosmetic surgery: Personality and individual difference predictors. Journal Body Image; 2009; 6; 7-13.

15. Delinsky S. S. (2005). Cosmetic surgery: A common and accepted form of self-improvement. Journal of Applied Social Psychology ;( 35); 20122028.

16. Almohanna Sh, Alswidan R, Alarfaj A ...et al. The number and Awareness of rhinoplasty and people preference of the shape of the nose. OMICS International conference. Series .com, 2nd International conference and exhibition on Rhinoplasty and Otology 2015; (63); 5:2; (63).

17. Opeyemi A, Ganiyu $\mathrm{O}$ and Peter B. Awareness and Attitude of Health Care Workers to cosmetic surgery in Osogbo, Nigeria .Surgery Research and Practice. Vol. 2014 (2014). (http://dx.doi. org/10.1155/2014/869567). 